ARTICLE OPEN

\title{
Effect of thermally induced structural disorder on the chemical durability of International Simple Glass
}

\author{
Frederic Angeli ${ }^{1}$, Thibault Charpentier $\mathbb{D}^{2}$, Patrick Jollivet ${ }^{1}$, Dominique de Ligny ${ }^{3}$, Michael Bergler $^{3}$, Alexander Veber $^{3}$, \\ Stéphane $\mathrm{Gin}^{1}$ and Hong $\mathrm{Li}^{4}$
}

While the influence of silicate oxide glass composition on its chemical durability is increasingly known, the contribution of structure only is less well understood, yet is crucial for an accurate description of aqueous alteration mechanisms. The effect of structural disorder can be investigated by varying the thermal history of the glass. Furthermore, the structural changes generated by selfirradiation in nuclear glasses can be compared with those induced by fast quenching. In the context of deep geological disposal of vitreous matrices, it is then challenging to address the structural impact on glass durability. Here, a borosilicate glass, the International Simple Glass, was fiberized to obtain a rapidly quenched sample. The quenching rate and fictive temperature were evaluated from in situ Raman and Brillouin spectroscopies. Multinuclear nuclear magnetic resonance was used to obtain insight into the effect of quenching on the pristine and altered glass structure. Higher bond angle distribution and lower mixing of alkalis were observed in the fast quenched glass. Some of $\mathrm{AlO}_{4}$ groups are then Ca-compensated, while a part of $\mathrm{BO}_{4}$ is transformed into $\mathrm{BO}_{3}$ units. The structural modifications increase the hydrolysis of the silicate network occurring in the forward rate regime at $90{ }^{\circ} \mathrm{C}$ by a factor of 1.4-1.8 depending on the $\mathrm{pH}$ value. Residual rate regime is similarly affected, more significantly at the beginning of the experiments conducted in silica saturated solutions. These findings prove that the reactivity of glass remains controlled by its structure under the various alteration regimes.

npj Materials Degradation (2018)2:31; doi:10.1038/s41529-018-0052-3

\section{INTRODUCTION}

The physico-chemical properties of silicate oxide glasses depend strongly on the nature and the relative proportions of the cations in their composition. The effects of these different elements on the chemical durability of glasses have been widely studied in various domains ranging from bioglasses with medical applications, ${ }^{1}$ materials used to regulate the $\mathrm{CO}_{2}$ cycle, ${ }^{2}$ lead crystal glass found in drinking vessels $s^{3}$ or vitreous matrices fabricated to confine radioactive waste. ${ }^{4}$ Understanding and modeling the behavior of nuclear waste packages in contact with groundwater is essential in the context of a deep geological disposal of vitreous matrices. $^{5}$ The resulting glass composition can vary widely depending on the waste composition; in this context the effects of the major elements of nuclear glasses on the various alteration regimes have been investigated in depth (see for example Gin et al. ${ }^{6}$ and the references therein). Their exact roles can however be difficult to ascertain since comparing different glasses involves both structural and chemical composition changes that are difficult to separate. To consider only structural changes, the chemical composition has to be kept constant. This can be achieved by modifying only the thermal history of the glass. Variations in the geometric and chemical disorder can then be evaluated as a function of the glass quenching rate. ${ }^{7}$

This approach may be particularly relevant to better understanding the structural damages induced by self-irradiation in nuclear glasses due to alpha decay of minor actinides. The displacement cascades induced by the recoil nuclei generated by alpha decay may induce the same kind of structural reorganizations in borosilicate glasses as do a very rapid thermal quench, leading to a new structural state at a fictive temperature higher than that of the pristine glass. ${ }^{8-10}$ When the whole volume is damaged, the accumulation of additional displacements in the glass structure does not modify it significantly anymore. Some properties, such as mechanical properties or density, reach then a plateau. $^{11}$ However, glasses submitted to external heavy-ion irradiation, simulating the effect of the recoil nuclei, show more significant effects than those seen in ${ }^{244} \mathrm{Cm}$ doped glasses. ${ }^{12,13}$ This behavior was attributed to the local annealing induced by the alpha particle's loss of electronic energy that partially repairs the damages generated by the recoil nuclei. ${ }^{14}$ Structural changes induced by self-irradiation could in particular affect the alteration behavior of glass matrices. Rapidly quenched glass may thus constitute a representative sample to investigate the chemical durability of these glasses in a laboratory setting. The hyperquenched glasses, as fibers, are not however easy to handle and reliable direct measurement of their fictive temperatures by the classical calorimetric method is challenging. ${ }^{15}$ To overcome this difficulty, we proposed here to use the Raman and Brillouin spectral signature of the cooling rate. Due to this new approach, an initial calibration of the spectroscopic evolution with the cooling rate was conducted on one bulk sample.

It has been shown that hydrogen diffusivity increases in sodalime glasses during alteration at $\mathrm{pH} 1$ when the fictive temperature increases. ${ }^{16}$ The lower density of these glasses may

\footnotetext{
${ }^{1}$ CEA, DEN, DE2D, SEVT, LCLT, CEA Marcoule, 30207 Bagnols-sur-Ceze, France; ${ }^{2}$ NIMBE, CEA, CNRS, Université Paris-Saclay, CEA Saclay, 91191 Gif-sur-Yvette Cedex, France; ${ }^{3}$ Institute of Glass and Ceramics, DMSE, University of Erlangen-Nuremberg, DE 91058 Erlangen, Germany and ${ }^{4}$ Nippon Electric Glass, Shelby, Pittsburg, PA 15024, USA Correspondence: Frederic Angeli (frederic.angeli@cea.fr)
}

Received: 9 April 2018 Revised: 27 August 2018 Accepted: 27 August 2018

Published online: 11 September 2018 
(a)
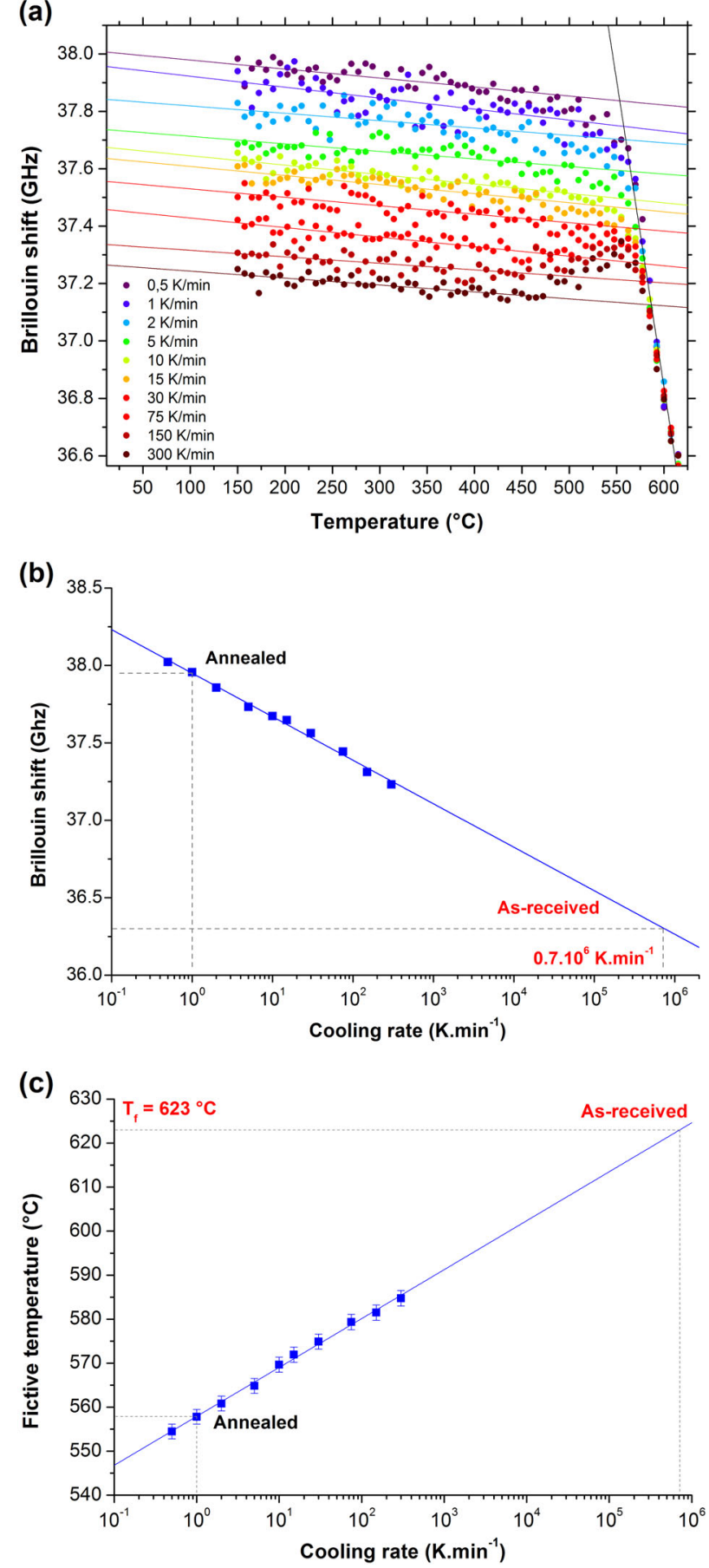

Fig. 1 a Brillouin shift as a function of temperature of ISG fibers cooled at different rates. b Brillouin shift extrapolated to room temperature as a function of the cooling rate of the fibers. The experimental error for confidence level of $95 \%$ was determined as $\pm 0.08 \%$ of the mean value by realizing a map in an homogeneous sample (corresponding here to $\pm 0.03 \mathrm{GHz}$ which is the size of the square). The cooling rate predicted for the as-received fibers from its Brillouin shift is indicated in red. c Fictive temperature of ISG fibers as a function of the cooling rate. The fictive temperature error bars were estimated to be the deviation of the linear fits in $\mathbf{a}$. The fictive temperature obtained for the as-received fibers from its cooling rate is indicated in red thus offer a more free volume that facilitates interdiffusion. A recent work was performed on dissolution in pure water of annealed and melt-quenched binary and ternary borosilicate glasses. ${ }^{17}$ It was found that glass compositions having the most significant structural variations after the thermal treatment, especially through boron coordinence, results in higher dissolution changes. We investigated here more complex glass composition through fibers, rapidly quenched during the drawing process and then annealed for reference (called in the paper "as-received fibers" and "annealed fibers", respectively). The International Simple Glass (ISG) was considered, a six-oxide reference glass widely used to examine the alteration in aqueous media of nuclear glasses. ${ }^{18}$ Brillouin and Raman spectroscopies are respectively sensitive to acoustic (providing volume information) and optical (sensitive to local atomic vibrations) phonons. These techniques were used here to link glass structural and volume changes to cooling rates and the corresponding fictive temperatures. Structural changes between annealed and as-received fibers, and then between the pristine and altered fibers were characterized by multinuclear solid-state NMR spectroscopy, which is sensitive to both geometric and chemical disorder. Alteration experiments were performed at various stages of the reaction and different $\mathrm{pHs}$. The forward dissolution rate, driven by hydrolysis mechanisms, was measured in media dilute enough to avoid any effect from the elements in solution on the alteration rate. The residual alteration rate, reflecting its long-term behavior, was obtained in initially silicon-saturated media (avoiding hydrolysis mechanisms ${ }^{19}$ ). Fibers ensured that the samples used in the dissolution experiments all had the same surface state, thus limiting surface-related uncertainties ${ }^{20}$ in the measured rates.

\section{RESULTS}

Thermal history and thermodynamic properties of glass samples Raman and Brillouin spectroscopies were used to evaluate the cooling temperature and fictive temperature of the glass fibers, in order to reveal their thermal history and quantify its effect. First of all, Brillouin and Raman calibration curves were measured in situ for bulk samples cooled at different rates. These data were then used to extract the quenching parameters of the as-received fibers. Differential scanning calorimetry (DSC) was used to address the thermodynamic properties of fibers.

Figure 1a shows the average position of the Brillouin shift for samples heated at $5 \mathrm{~K} \mathrm{~min}^{-1}$ between 150 and $620^{\circ} \mathrm{C}$ after being subjected to various cooling rates between $0.5 \mathrm{~K} \mathrm{~min}^{-1}$ and $300 \mathrm{~K}$ $\mathrm{min}^{-1}$. At the beginning of the heating process, the Brillouin shift is very sensitive to the initial cooling rate of the glass. This is consistent with the fact that the density and elastic properties of the glass decrease with the increase in quenching rate. ${ }^{21,22}$ Between 150 and $450{ }^{\circ} \mathrm{C}$, the Brillouin curves for the samples are all parallel, with a shallow slope. This evolution corresponds to thermal expansion, which is weakly sensitive to the initial cooling rate. Above the glass transition temperature $\left(T_{g}=575^{\circ} \mathrm{C}\right)$, the Brillouin curves merge and decrease sharply, reflecting the complete relaxation of the glass structure. Some differences in behavior are observed between $450^{\circ} \mathrm{C}$ and $T_{g}$. In the samples cooled more slowly, the glass structure remains into the equilibrated state during heating at $5 \mathrm{~K} \mathrm{~min}^{-1}$ and the transition to higher temperatures is smooth. For the samples cooled more rapidly on the other hand, at $75 \mathrm{~K} \mathrm{~min}^{-1}$ and above, heating at $5 \mathrm{~K}$ $\mathrm{min}^{-1}$ partially relaxes the glass before it becomes liquid like at higher temperatures.

Extrapolating the Brillouin curves to room temperature reveals the Brillouin shift corresponding to each of the quenching rates and yields the linear relationship shown in Fig. 1b. The Brillouin shift is greater, the slower the cooling rate is, in agreement with previous measurement on soda-lime glasses. ${ }^{21}$ Extrapolating these 

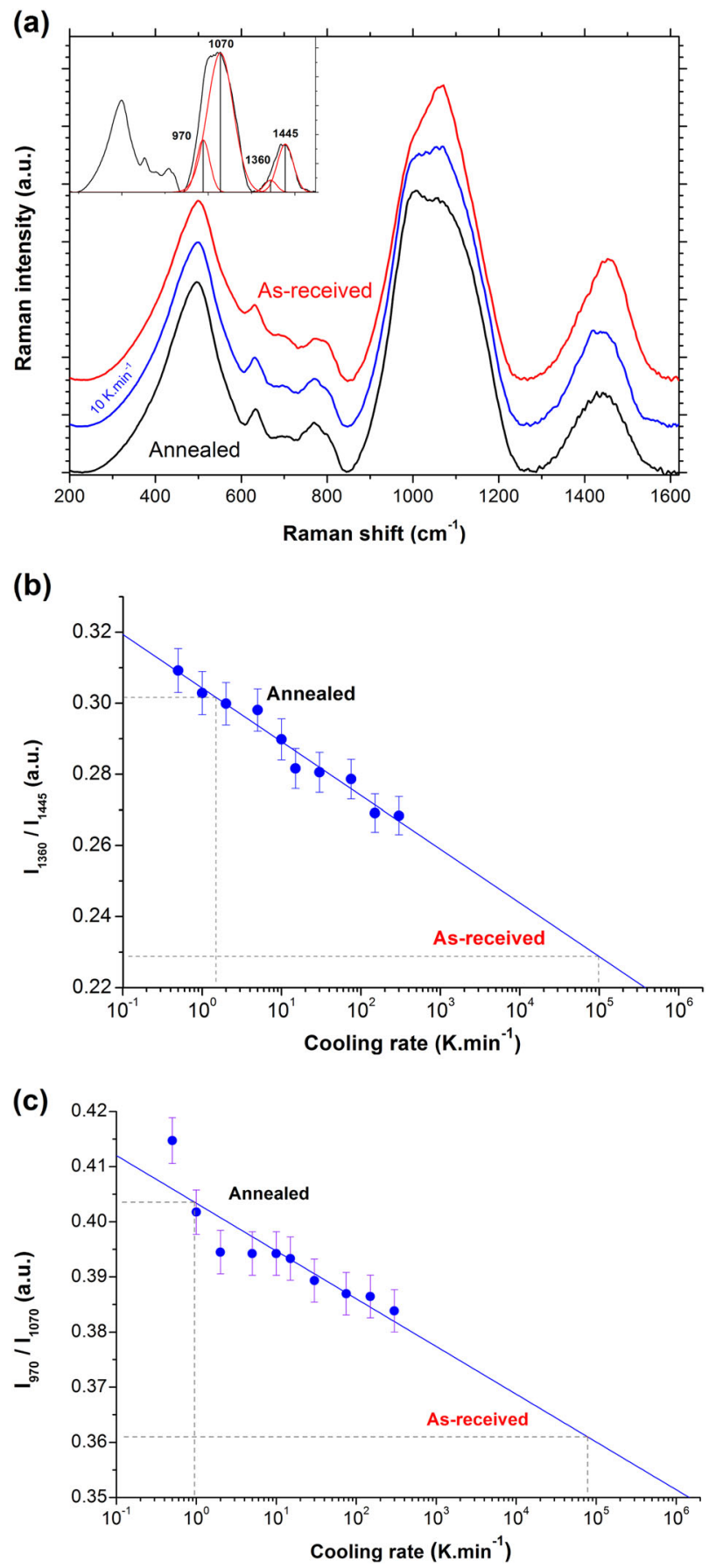

Fig. 2 a Raman spectra of the as-received and annealed ISG fibers, and of ISG cooled at $10 \mathrm{~K} \mathrm{~min}^{-1}$. The inset shows the fit of the bands around $1000 \mathrm{~cm}^{-1}$ and $1400 \mathrm{~cm}^{-1}$. b, c Intensity ratios as a function of cooling rate of the peaks (b) at $1360 \mathrm{~cm}^{-1}$ over the one at $1445 \mathrm{~cm}^{-1}$ and (c) at $970 \mathrm{~cm}^{-1}$ over the one at $1070 \mathrm{~cm}^{-1}$. The error bars were taken as the standard deviation for the Gaussian fitting of the related peaks

shifts to the value measured for the as-received fibers (quenched during the drawing process) gives a quenching rate of $0.7 \times 10^{6} \mathrm{~K}$ $\mathrm{min}^{-1}$ (Fig. 1b). The intersections between the glass linear extrapolation and the liquid one in the Brillouin curves (Fig. 1a), which occur at the transition between the supercooled liquid and the frozen glass, give the Brillouin fictive temperature of the fibers. Figure 1c shows that the fictive temperature increases linearly with the cooling rate. The fictive temperature deduced for the as- received fibers (from the previous determined quenching rate of $0.7 \times 10^{6} \mathrm{~K} \mathrm{~min}^{-1}$ ) is $623^{\circ} \mathrm{C}$. The same approach gives a fictive temperature for the annealed fibers of $558^{\circ} \mathrm{C}$, i.e., $65^{\circ} \mathrm{C}$ lower.

Complementary glass local structural information can be obtained for specific structural groups by using the same method with Raman spectroscopy. We have shown previously on borosilicate glasses that the vibrations of $\mathrm{SiO}_{4}$ and $\mathrm{BO}_{3}$ groups are sensitive to variations of the glass fictive temperature. ${ }^{7}$ Recent molecular dynamics simulations clearly highlighted these effects in ternary sodium borosilicate glasses in relation with the cooling rate. ${ }^{23}$ Figure $2 a$ compares the Raman spectra of as-received and annealed fibers and of the ISG bulk glass cooled at an intermediate rate $\left(10 \mathrm{~K} \mathrm{~min}^{-1}\right)$. The inset shows contribution of the Gaussian components typically assigned to $\mathrm{SiO}_{4}$ and $\mathrm{BO}_{3}$ species whose variations were determined as a function of the cooling rate in Fig. $2 \mathrm{~b}, \mathrm{c}$. The band around $1450 \mathrm{~cm}^{-1}$, which consist of two Gaussian components, is assigned to stretching vibrations in $\mathrm{BO}_{3}$ units. ${ }^{24,25}$ We observed previously that the increase in intensity of this band was well correlated with the increase of the signal assigned to $\mathrm{BO}_{3}$ units in ${ }^{11} \mathrm{~B}$ MAS NMR spectra. ${ }^{26}$ The narrow band around $630 \mathrm{~cm}^{-1}$, assigned to vibrations from danburite-type $\mathrm{B}_{2} \mathrm{O}_{7}-\mathrm{Si}_{2} \mathrm{O}_{7}$ rings, ${ }^{27}$ is slightly weaker in the spectrum of the as-received fibers. The ratio of the intensities of the peaks at $1360 \mathrm{~cm}^{-1}$ and $1445 \mathrm{~cm}^{-1}$ is plotted in Fig. $2 \mathrm{~b}$ for cooling rates ranging from 0.5 to $300 \mathrm{~K} \mathrm{~min}^{-1}$. By using least-square linear regression analysis, a cooling rate of about $10^{5} \mathrm{~K} \mathrm{~min}^{-1}$ was obtained from the extrapolation of the data for the as-received fibers. The same approach was used for gaussian components at lower frequencies, in the large band between $830 \mathrm{~cm}^{-1}$ and $1275 \mathrm{~cm}^{-1}$ associated with the symmetric stretching modes in $\mathrm{SiO}_{4}$ tetrahedra. ${ }^{28,29}$ Plotting the ratio of the intensities of the peaks at $970 \mathrm{~cm}^{-1}$ and $1070 \mathrm{~cm}^{-1}$ as a function of the quenching rate yields a cooling rate for the as-received fibers of the same order as the one obtained from the boron vibrations (Fig. 2c). These values are about one order of magnitude lower than those calculated from the Brillouin data (close to $10^{6} \mathrm{~K} \mathrm{~min}^{-1}$ ). Another notable difference between these two datasets is that while the evolution of the Brillouin shift shows complex relaxation process between $450^{\circ} \mathrm{C}$ and $T_{g}$, no equivalent perturbation was observed in the Raman data (peak intensity ratio vs temperature, Fig. 3).

Using the onset of the glass transition ${ }^{30}$ for the sample cooled at $10 \mathrm{~K} \mathrm{~min}^{-1}$, the glass transition temperature $T_{g}$ was measured at $573 \pm 1{ }^{\circ} \mathrm{C}$. This value is in good agreement with previous works on ISG glass reporting $575^{\circ} \mathrm{C} .{ }^{22}$ The difference in molar heat capacity near $T_{g}, \Delta C_{p}\left(T_{g}\right)$, between the annealed and as-received fibers was

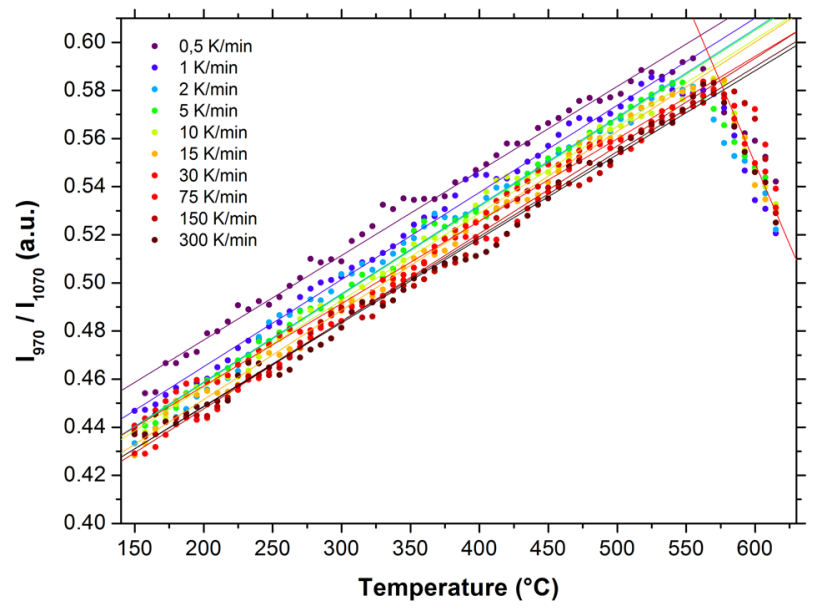

Fig. 3 Evolution of the intensity ratio of the fitted Raman band at $970 \mathrm{~cm}^{-1}$ over one at $1070 \mathrm{~cm}^{-1}$ as a function of temperature for ISG fibers cooled at different rates 
measured to be $28.9 \pm 0.3 \mathrm{~J} \mathrm{~mol}^{-1} \mathrm{~K}^{-1}$ which is comparable to the value of $28.1 \pm 0.2 \mathrm{~J} \mathrm{~mol}^{-1} \mathrm{~K}^{-1}$ given in ref. ${ }^{31}$ Using the respective Brillouin fictive temperature of the fibers $\left(T_{f 1}=558^{\circ} \mathrm{C}\right.$ for the annealed ones and $T_{f 2}=623^{\circ} \mathrm{C}$ as-received) and assuming that the heat capacity does not vary much with the fictive temperature and that $\Delta C_{P}$ remains constant over the fictive temperature interval considered, this difference in heat capacity can be used to calculate the variations in thermodynamic properties. The difference of enthalpies of vitrification,

$\Delta H_{v 2}-\Delta H_{v 1}=\int_{T_{f 1}}^{T_{f 2}}\left(C_{P_{1}}^{\circ}-C_{P g}^{\circ}\right) \mathrm{d} T \approx \Delta C_{P}\left(T_{g}\right) \times\left(T_{f 2}-T_{f 1}\right)$

in which $C_{P,}^{\circ}$ and $C_{P g}^{\circ}$ are respectively the heat capacities of the liquid and the glass, is thus $1.88 \mathrm{~kJ} \mathrm{~mol}^{-1}$. Likewise, the difference in configurational entropy, calculated using

$S^{\circ}(0)_{2}-S^{\circ}(0)_{1}=\int_{T_{f 1}}^{T_{f 2}} \frac{C_{P_{1}}^{\circ}-C_{P g}^{\circ}}{T} \mathrm{~d} T \approx \Delta C_{P}\left(T_{g}\right) \times \ln \left(\frac{T_{f 2}}{T_{f 1}}\right)$

is found to be $2.18 \mathrm{~J} \mathrm{~mol}^{-1} \mathrm{~K}^{-1}$. This gives a significant variation of Gibbs energy of formation,

$$
\Delta G_{f}^{\circ}(298)_{2}-\Delta G_{f}^{\circ}(298)_{1}=\left(\Delta H_{v 2}-\Delta H_{v 1}\right)-298\left(S^{\circ}(0)_{2}-S^{\circ}(0)_{1}\right)
$$

of $1.23 \mathrm{~kJ} \mathrm{~mol}^{-1}$ between the two samples.

\section{Pristine glass structure}

The NMR parameters for the different nuclei are listed in Table 1. As expected, the annealed fibers are slightly denser (about 1\%) than the as-received fibers (Table 2).

Significant changes are observed between the ${ }^{11} \mathrm{~B}$ MAS NMR spectra of the as-received and annealed fibers (Fig. 4a). The best fits obtained for the two spectra using methods described elsewhere, ${ }^{26}$ put the proportion of tetrahedral boron in the annealed fibers at $50.0 \%$ vs $41.1 \%$ in the as-received ones (Fig. $5 \mathrm{a}$,

Table 1. Parameters used to fit the NMR spectra of ISG fibers

\begin{tabular}{|c|c|c|c|}
\hline & & As-received & Annealed \\
\hline \multirow[t]{3}{*}{$\mathrm{Na}$} & $\delta_{\text {iso }}(\mathrm{ppm})$ & -11.1 & -10.9 \\
\hline & $C_{Q}(\mathrm{MHz})$ & 2.2 & 2.2 \\
\hline & FWHM (ppm) & 27.7 & 26.8 \\
\hline \multirow[t]{3}{*}{ Al } & $\delta_{\text {iso }}(\mathrm{ppm})$ & 61.0 & 61.0 \\
\hline & $C_{Q}(\mathrm{MHz})$ & 5.2 & 4.7 \\
\hline & FWHM (ppm) & 21.6 & 19.7 \\
\hline \multirow[t]{4}{*}{$\mathrm{BO}_{4}(3 \mathrm{Si}, 1 \mathrm{~B})$} & $\delta_{\text {iso }}(\mathrm{ppm})$ & 0.1 & \\
\hline & $C_{Q}(\mathrm{MHz})$ & 0.6 & \\
\hline & FWHM (ppm) & 3.6 & \\
\hline & Population & 30.6 & 42.1 \\
\hline \multirow[t]{4}{*}{$\mathrm{BO}_{4}(4 \mathrm{Si}, 0 \mathrm{~B})$} & $\delta_{\text {iso }}(\mathrm{ppm})$ & -1.7 & \\
\hline & $C_{Q}(\mathrm{MHz})$ & 0.2 & \\
\hline & FWHM (ppm) & 3.1 & \\
\hline & Population & 10.5 & 7.9 \\
\hline \multirow[t]{3}{*}{$\mathrm{BO}_{3}$ ring } & $\delta_{\text {iso }}(\mathrm{ppm})$ & 17.2 & \\
\hline & $C_{Q}(\mathrm{MHz})$ & 2.5 & \\
\hline & Population & 34.0 & 36.4 \\
\hline \multirow[t]{3}{*}{$\mathrm{BO}_{3}$ non-ring } & $\delta_{\text {iso }}(p p m)$ & 13.4 & \\
\hline & $C_{Q}(\mathrm{MHz})$ & 2.7 & \\
\hline & Population & 24.9 & 13.6 \\
\hline $\mathrm{BO}_{4}$ total & Population & 41.1 & 50.0 \\
\hline
\end{tabular}

the fitting parameters are listed in Table 1). Rapid quenching is thus associated with a decrease of $8.9 \%$ in the proportion of $\mathrm{BO}_{4}$ groups. The chemical shift of the $\mathrm{BO}_{4}$ line is also more negative in the spectrum of the as-received fibers. This peak comes from boron atoms connected only to silicon atoms $\left({ }^{4} \mathrm{~B}(4 \mathrm{Si})\right)$ and from boron atoms connected to three silicon and one boron atoms $\left({ }^{4} \mathrm{~B}\right.$ $(3 \mathrm{Si}, 1 \mathrm{~B})) .{ }^{26,32}$ Since the latter has more positive chemical shifts than the former, the observed shift in the $\mathrm{BO}_{4}$ peak indicates that there is a larger proportion of ${ }^{4} \mathrm{~B}(4 \mathrm{Si})$ sites in the as-received fibers.

The ${ }^{11} B$ MQMAS NMR spectra shown in Fig. 6a provide more accurate information on the distribution of boron sites in the fibers. The distributions of isotropic NMR shifts are broader in the as-received fibers than in the annealed ones, for both $\mathrm{BO}_{3}$ and $\mathrm{BO}_{4}$ groups, as highlighted by the projections onto the isotropic NMR shift axis (Fig. 6b).

Figure $4 \mathrm{~b}$ shows that there is no significant change between the ${ }^{29} \mathrm{Si}$ MAS NMR spectra of the as-received and annealed fibers. This does not necessarily mean that the $Q^{n}$ ( $n$ indicating the number of bridging oxygens per tetrahedron) speciation of the $\mathrm{SiO}_{4}$ groups is identical in the two glasses. The ${ }^{29} \mathrm{Si}$ chemical shift of silicon groups is sensitive to the nature of their next-nearest neighbors. In previous works ${ }^{7,33}$ we showed that the effects of depolymerization in the ${ }^{29} \mathrm{Si}$ NMR spectra were masked by an increased presence of boron as a next-nearest neighbor. It is generally expected that substitution of one bonded silicon for one aluminum impact the isotropic chemical shift of the central silicon by an increase of about 4-5 ppm. ${ }^{34}$ Similar increase has been reported for Si-O-B linkages, ${ }^{35,36}$ but shown to depend on the boron speciation ${ }^{33}$ (no change is observed for $\mathrm{Si}-\mathrm{O}-\mathrm{B}^{\mathrm{III}}$ in contrast to $\mathrm{Si}-\mathrm{O}-\mathrm{B}^{\mathrm{IV}}$ ). Because of the glass composition complexity, these data are therefore inconclusive as to possible differences in the degree of polymerization in the as-received and annealed fibers.

The single broad line in the ${ }^{23} \mathrm{Na}$ MAS NMR spectrum of the asreceived fibers is slightly wider than the corresponding line for the annealed fibers (Fig. 7a). The interpretation of the width of ${ }^{23} \mathrm{Na}$ MAS NMR lines only, indicative of high substantial disorder, is tricky. ${ }^{23} \mathrm{Na}$ spin-echo experiments measuring ${ }^{23} \mathrm{Na}-{ }^{23} \mathrm{Na}$ dipolar couplings ${ }^{37}$ were performed to investigate the spatial distribution of sodium. Indeed, the spin echo experiment refocuses most of the NMR interactions (giving the echo), except the homonuclear dipolar interactions which are only averaged out by MAS (to first order). Decay of the spin echo is therefore dominated by the effects of the ${ }^{23} \mathrm{Na}-{ }^{23} \mathrm{Na}$ dipolar interactions. Figure $7 \mathrm{~b}$ shows that the ${ }^{23} \mathrm{Na}$ spin-echo signal from the as-received fibers decreases more rapidly, indicating that the ${ }^{23} \mathrm{Na}-{ }^{23} \mathrm{Na}$ dipolar couplings are much stronger than in the annealed fibers. This suggests that sodium is distributed less homogeneously in the as-received fibers.

The ${ }^{27} \mathrm{AI}$ MAS NMR line from the as-received fibers is broader than the one from the annealed ones (Fig. 7c), but no difference in the coordination of the aluminum atoms (tetrahedral in both cases, as confirmed by ${ }^{27} \mathrm{Al}$ MQMAS spectra given in Fig. 8) was observed. Differences in the chemical environment of aluminum atoms, particularly concerning their charge compensation, can be evaluated using the dipolar couplings between ${ }^{23} \mathrm{Na}$ and ${ }^{27} \mathrm{Al}$ nuclei, measured by heteronuclear rotational-echo double-resonance (REDOR) experiments. ${ }^{38}$ The principle of REDOR, based on the spin echo experiment, is to collect two spin echo decay curves: the first denoted $S_{0}(t)$ using the standard pulse sequence $90^{\circ}$-т$180^{\circ}$ - $\tau$; the second $S(t)$ applying on the second channel a train of rotor-synchronized refocusing $180^{\circ}$ pulses (one at each rotor period and one in the middle of each rotor period), so that heteronuclear dipolar interactions are selectively reintroduced. The REDOR signal is obtained as $\Delta S(t)=\left(S_{0}(t)-S(t)\right) / S_{0}(t)$ and only incorporates the effects of the dipolar heteronuclear interactions. Figure $7 \mathrm{~d}$ clearly shows that the ${ }^{23} \mathrm{Na}\left\{{ }^{27} \mathrm{Al}\right\}$ REDOR signal from the as-received fibers is weaker, indicating that there are fewer aluminum atoms in the vicinity of sodium nuclei. 
Table 2. Density and alteration rates for ISG fibers

\begin{tabular}{|c|c|c|c|c|c|c|}
\hline Glass fibers & Density & \multicolumn{3}{|c|}{ Forward dissolution rate $\left(\mathrm{g} \mathrm{m}^{2} \mathrm{~d}^{-1}\right)$} & $\begin{array}{l}\text { Mean residual rate }\left(\mathrm{g} \mathrm{m}^{2} \mathrm{~d}^{-1}\right) \\
\mathrm{pH} 9\end{array}$ & Equivalent thickness (nm) \\
\hline Annealed & 2.509 & 0.21 & 0.46 & 5.82 & $4.0 \times 10^{-3}$ & 444 \\
\hline
\end{tabular}

Residual rates were calculated by linear regression between 72 and 224 days. The uncertainty associated with the rates is $\pm 10 \%$.

(a)

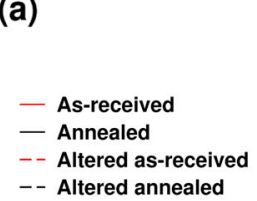

- - Altered annealed

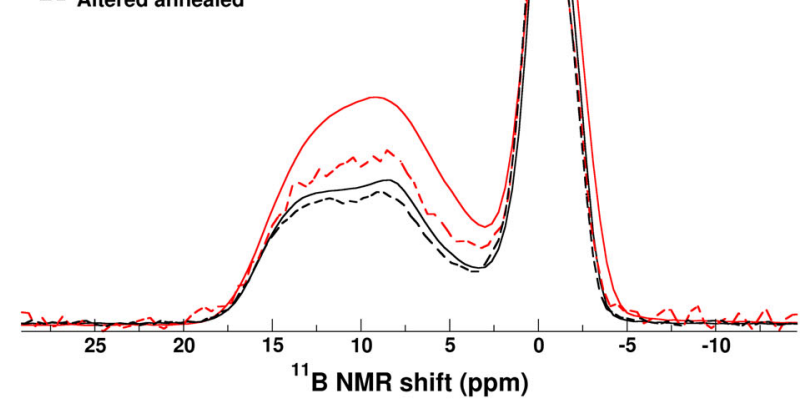

(b)

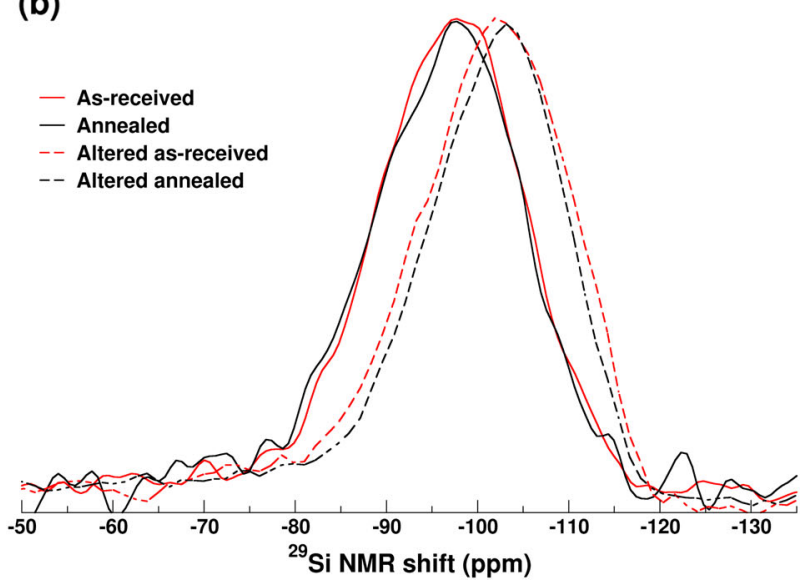

Fig. 4 a ${ }^{11} \mathrm{~B}$ and $\mathbf{b}^{29} \mathrm{Si}$ MAS NMR spectra of as-received and annealed ISG fibers, either pristine (solid lines) or after 100 days of alteration at $\mathrm{pH} 7$ and $90{ }^{\circ} \mathrm{C}$ (dashed lines). The spectra are scaled to the same height

Glass alteration far and close to saturation

Two types of experiments were performed on the as-received and annealed fibers to investigate their initial and long-term alteration behavior, namely when the alteration process in aqueous solutions is governed by hydrolysis of the silicate network, and after by the formation of a passivating layer. ${ }^{19,39-41}$

The first series of experiments were performed under forward dissolution rate conditions at $90^{\circ} \mathrm{C}$ and $\mathrm{pHs}$ of $6,7.5$, and 9. The dissolution rates obtained from the measured silicon release rates are summarized in Table 2 and compared in Fig. 9a. Measurements of the aluminum concentration showed that the normalized mass losses were very close to that of silicon (data not shown). The $\mathrm{pH}$ dependence coefficient of the forward dissolution rates for both types of fibers is 0.4 , in agreement to the value determined for SON68 glass. ${ }^{42}$ The forward dissolution rates of the (a)

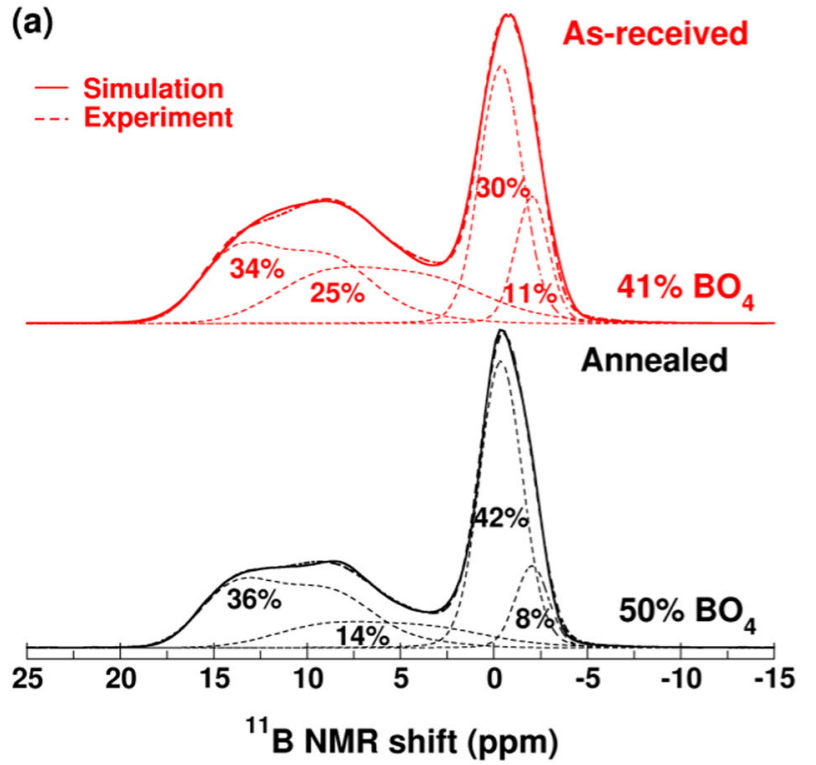

(b)

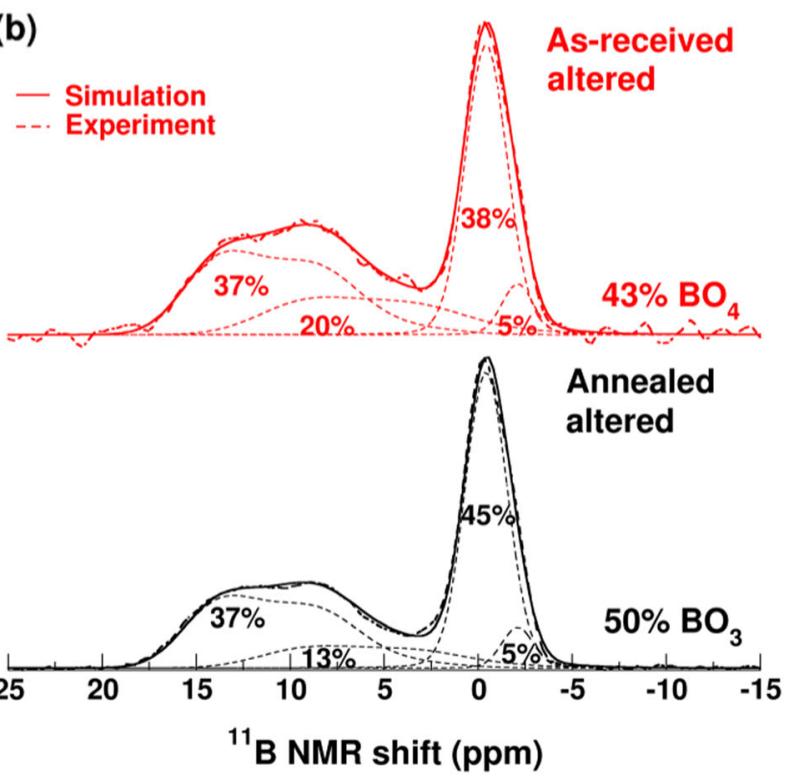

Fig. 5 Measured and simulated ${ }^{11} B$ MAS NMR spectra of the asreceived and annealed ISG $\mathbf{a}$ pristine fibers and $\mathbf{b}$ altered fibers, using the same peak positions and linewidths for all the spectra

as-received fibers are higher under all three $\mathrm{pH}$ conditions than those of the annealed fibers, by a factor of 1.4-1.8.

Residual alteration rates were measured in solutions at $\mathrm{pH} 9$ initially saturated with respect to amorphous silica, to investigate the effect of the alteration layer that forms on ISG fibers on its subsequent alteration. ${ }^{19}$ No secondary phases precipitate on the 
(a)
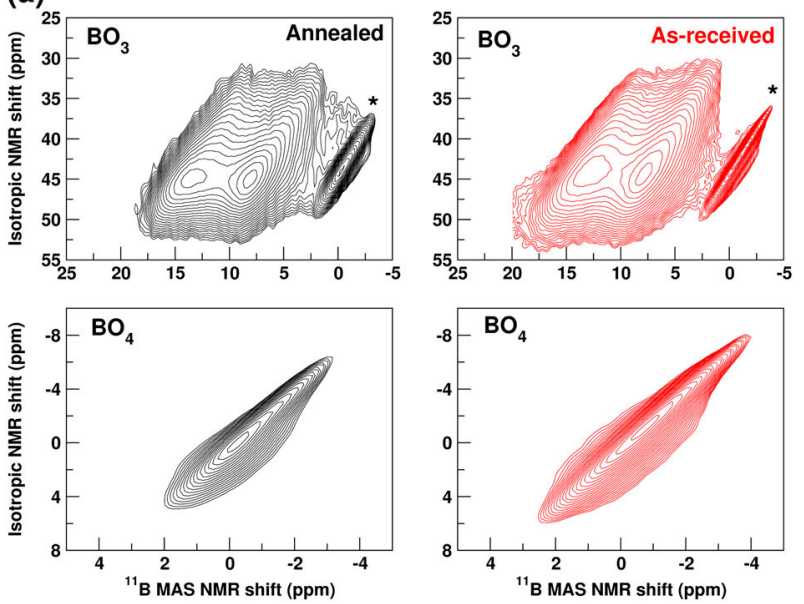

(b)

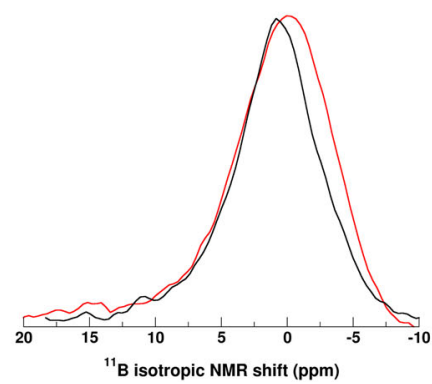

As-receive
Annealed

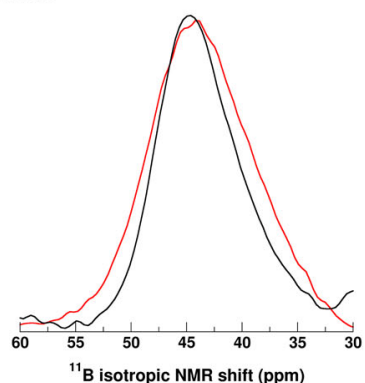

Fig. 6 a ${ }^{11} \mathrm{~B}$ MQMAS NMR spectra of as-received and annealed ISG fibers (upper panels, $\mathrm{BO}_{3}$ region; lower panels, $\mathrm{BO}_{4}$ region) $\left(^{*}\right.$ : spinning sidebands). $\mathbf{b}$ Projections onto the isotropic NMR shift axis of the spectra shown in part a

surface of ISG as it becomes altered, such that there is a direct link between the alteration rate of the glass and the passivating properties of the alteration layer. ${ }^{6,43}$ The residual rate calculated according to the first data points (both from the $\mathrm{Na}$ and $\mathrm{B}$ release in solution) for the as-received fibers is about 2.4 times higher than the value obtained for the annealed fibers. This difference diminishes with time at about 1.4 considering the data points between 72 and 244 days (Table 2). Figure 9b shows the equivalent thicknesses of the altered layers at the end of the experiment that are about 2.2 times higher for as-received fibers. Analyses of the solutions indicate that the compositions of the alteration layers are almost identical (Table 3).

To investigate the structure of the alteration layer by NMR, a final experiment was performed under conditions chosen to maximize the proportion of the altered glass. Keeping constant the solution at $\mathrm{pH} 7$ yielded a fraction of altered glass of $91 \%$ for the as-received fibers and $60 \%$ for the annealed fibers (calculated from solution analyses from boron release) after 100 days at $90^{\circ} \mathrm{C}$. This difference is consistent with the measurements performed at $\mathrm{pH}$ 9. As for the pristine samples, there is no observable change between the ${ }^{29} \mathrm{Si}$ MAS NMR spectra of the two types of fibers after alteration. Figure $4 \mathrm{~b}$ shows however that the single broad peak observed in each case appears at a more negative chemical shift for the altered than the pristine glasses, highlighting the structural rearrangements occurring in the altered layer. The ${ }^{29} \mathrm{Si}$ chemical shift of silicate groups becomes more negative as the number of bridging oxygens increases (i.e., as the connectivity of the glass network increases); as shown above however, this variation could also be influenced by next-nearest neighbor effects. On the other hand, comparison of the ${ }^{11} \mathrm{~B}$ MAS NMR spectra in Fig. 4 a reveals that the proportion of trigonal boron is lower in the altered samples, mainly for the as-received fibers, indicating that $\mathrm{BO}_{3}$ groups are released preferentially over $\mathrm{BO}_{4}$ groups. Considering that $91 \%$ of the quenched fiber was altered and subtracting the pristine glass contribution, the resulting $\mathrm{BO}_{3}$ proportion in the alteration layer is about $56.5 \%$ (58.9\% in the as-received fibers). The proportion of boron species for altered fibers is given in Fig. $5 b$.

\section{DISCUSSION}

The Raman, Brillouin, and NMR spectroscopy data collected in this study provide complementary information on the structural changes induced by very rapid quenching of soda-lime aluminoborosilicate glass and the resulting effects on its chemical durability. Studying quenched samples reveals the effect of the thermal history, and thus of the fabrication process, on the properties of the glass. This approach can also be relevant to investigate the radiation damages in nuclear glasses, whose effects are similar to those of quenching. ${ }^{8}$

The Raman spectroscopy study might suggest that increasing the cooling rate should increase the average number of bridging oxygens per $\mathrm{SiO}_{4}$ group since the peak contribution at $1070 \mathrm{~cm}^{-1}$, usually assigned to high $Q^{n}$ species, increases compared to the contribution at $970 \mathrm{~cm}^{-1}$, usually assigned to lower $Q^{n}$ species ${ }^{44}$ (Fig. 2a). This observation is in agreement with in situ Raman data obtained on ISG glass with the increase of temperature. ${ }^{22}$ An opposite trend was noted for sodium borosilicate glasses (without $\mathrm{Zr}$ and $\mathrm{Al}$ ), whose degree of polymerization, as expected, was found to be lower the higher the fictive temperature was. ${ }^{7,8}$ However, it is worth noting that the $\mathrm{Si}-\mathrm{O}$ stretching region of the $Q^{n}$ species is strongly affected by the presence of the T secondneighbors of $\mathrm{Si}(\mathrm{T}=\mathrm{Zr}, \mathrm{Al}, \mathrm{B})$. Then, the decrease of the band at $970 \mathrm{~cm}^{-1}$ may be more likely related to the decrease of the $\mathrm{Si}$ atoms connected to two other second-neighbors than $\mathrm{Si}, \mathrm{Q}^{4}(2 \mathrm{~T})$ units, overlapping the $Q^{2}$ units. $^{13}$ As we noticed for the boron with an increase of ${ }^{4} \mathrm{~B}(4 \mathrm{Si})$ instead of ${ }^{4} \mathrm{~B}(3 \mathrm{Si}, 1 \mathrm{~B})$ sites, quenched glasses could then limit mixing between network formers around $\mathrm{Si}$ atoms. The slight shift in the $\mathrm{Si}-\mathrm{O}-\mathrm{Si}$ bending mode from $496 \mathrm{~cm}^{-1}$ in the annealed sample to $500 \mathrm{~cm}^{-1}$ in the asreceived fibers, suggests that the average $\mathrm{Si}-\mathrm{O}-\mathrm{Si}$ angle decreases with the increase of glass fictive temperature. ${ }^{45}$ It has been reported that $\mathrm{Si}-\mathrm{O}-\mathrm{Si}$ bond angles tend to be smaller with the increase of $\mathrm{Na}$ in the vicinity of the Si groups, ${ }^{46}$ which is in agreement here with the additional $\mathrm{Na}$ near $\mathrm{Si}$ in the as-received fibers coming from charge compensation of $\mathrm{BO}_{4}$ groups in the annealed fibers.

The break in the overall trend observed in the Brillouin data between $450^{\circ} \mathrm{C}$ and $T_{g}$ for the glasses cooled most rapidly (Fig. 1a) was not observed in the Raman data (Fig. 3). This may be related to the lower relaxation energy of the groups probed by Raman spectroscopy which characterize the short-range order in the glass through iono-covalent bonds. At this length scale, the liquid to solid transition is similar at all quenching rates. The fact that the quenching rate determined from the Raman data for the asreceived fibers $\left(10^{5} \mathrm{~K} \mathrm{~min}^{-1}\right)$ is close to a factor of ten lower than the value extrapolated from the Brillouin data $\left(0.7 \times 10^{6} \mathrm{~K} \mathrm{~min}^{-1}\right)$ may also be due to the different length scales probed by the two techniques (short for the former and long for the latter). Fictive temperatures are traditionally determined by calorimetry, a bulk technique that is therefore presumably closer to the Brillouin than to the Raman data. The relatively good agreement between DSC and Brillouin is here confirmed by the fact that the Brillouin fictive temperature for a glass with a slow cooling rate of $10 \mathrm{~K} \mathrm{~min}^{-1}$ is of $570 \pm 2{ }^{\circ} \mathrm{C}$, within the error bar of the $T_{g}$ at $573 \pm 1{ }^{\circ} \mathrm{C}$ determined by DSC. Furthermore, the larger dispersion in the Raman measurements makes the extrapolations to determine the quenching rate of the as-received fibers more uncertain. The values obtained from the Brillouin data for the quenching rate 
(a)

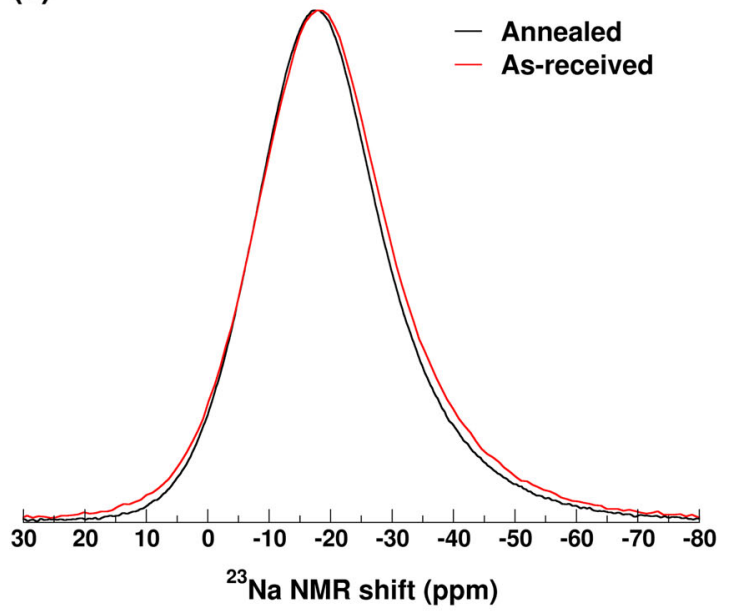

(c)

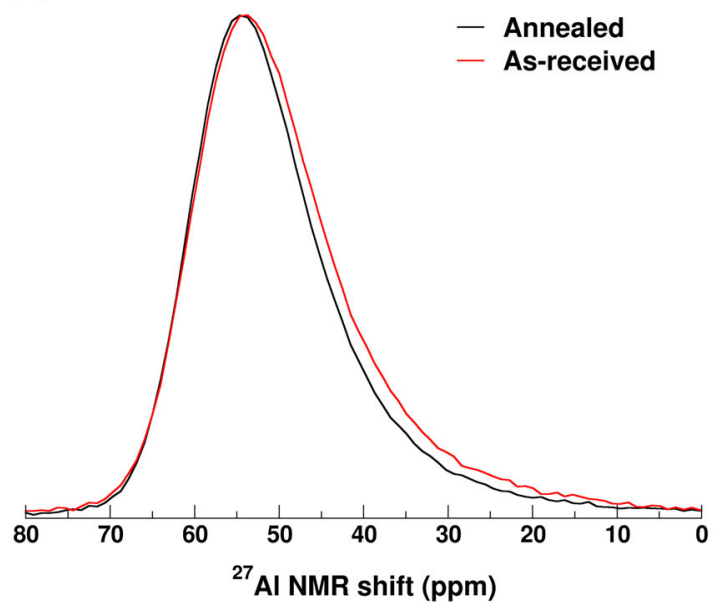

(b)

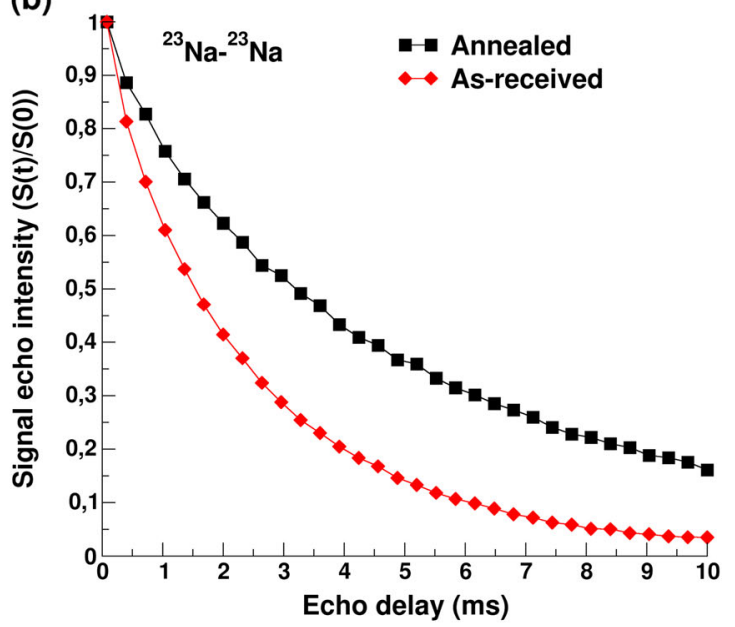

(d)

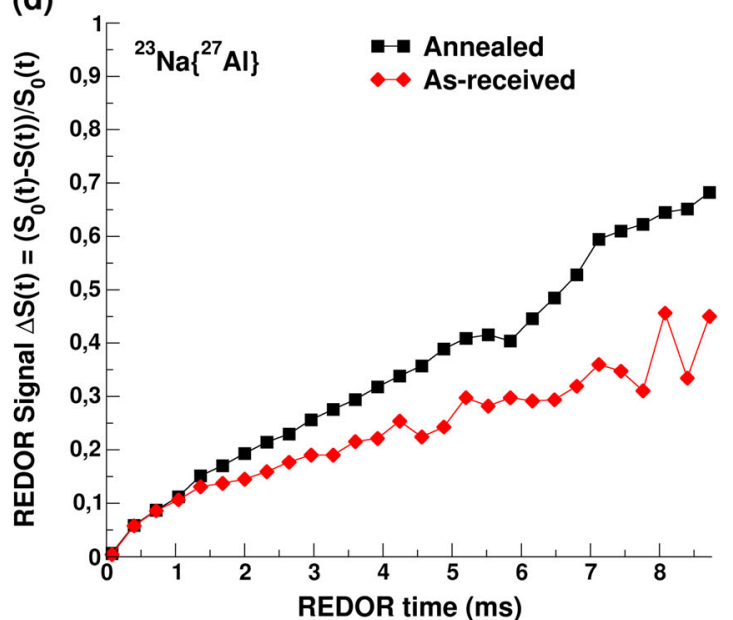

Fig. 7 a ${ }^{23} \mathrm{Na}$ MAS NMR spectra. $\mathbf{b}{ }^{23} \mathrm{Na}$ spin-echo intensity as a function of the spin-echo delay. $\mathbf{c}^{27} \mathrm{Al}$ MAS NMR spectra, and $\mathbf{d}{ }^{23} \mathrm{Na}\left\{{ }^{27} \mathrm{Al}\right\}$ rotational-echo double-resonance (REDOR) intensity as a function the REDOR time for as-received and annealed ISG fibers

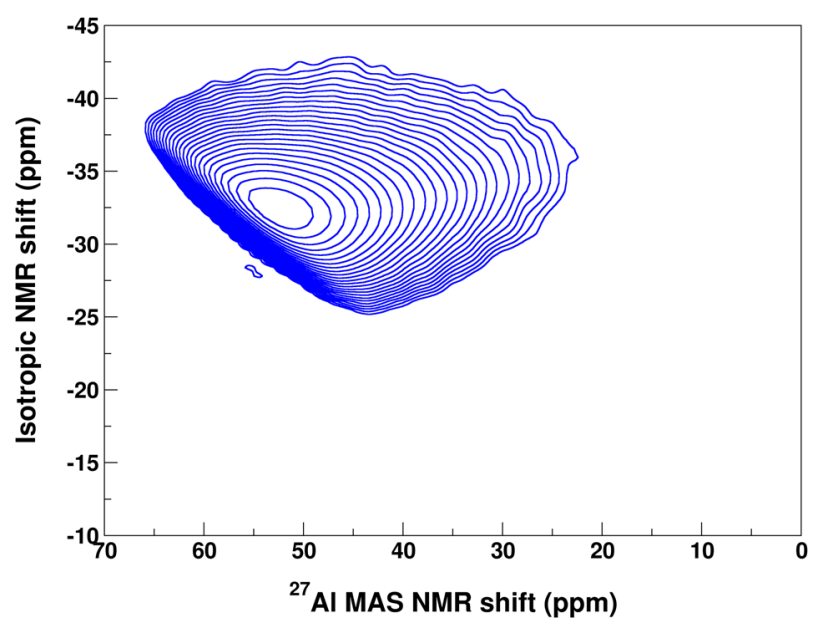

Fig. $8{ }^{27} \mathrm{Al}$ MQMAS NMR of the as-received ISG fibers

$\left(0.7 \times 10^{6} \mathrm{~K} \mathrm{~min}^{-1}\right)$ and the fictive temperature $\left(623^{\circ} \mathrm{C}\right)$ therefore seem more reliable.

Multinuclear NMR first provides information on the structural disorder induced by rapid quenching. The ${ }^{11} \mathrm{~B}$ MQMAS spectra (Fig. 6) show that the isotropic chemical shift distribution $\left(\delta_{\text {iso }}\right)$ is broader in the as-received fibers than once they are annealed. Since it was shown that ${ }^{11} \mathrm{~B} \delta_{\text {iso }}$ is sensitive to the $\mathrm{B}-\mathrm{O}-(\mathrm{B}, \mathrm{Si}$, or $\mathrm{Al})$ bond angles in the glass, ${ }^{33}$ these data suggest that the bond angle distribution of the as-received fibers is broader, thus reflective of an increased geometrical disorder. Regarding the cations in the glass, the ${ }^{23} \mathrm{Na}$ spin-echo experiments highlight that sodium is distributed more heterogeneously in the as-received fibers (the distance to the neighboring sodium atoms is shorter on average), possibly starting to form some alkaline clusters or local enrichment. In glasses with compositions similar to that of ISG, sodium acts mainly as a charge compensator, first for $\mathrm{AlO}_{4}$ and then, for the residual $\mathrm{Na}$ available, for $\mathrm{BO}_{4}$ groups. ${ }^{47}$ The ${ }^{23} \mathrm{Na}-{ }^{27} \mathrm{Al}$ REDOR experiments clearly show that the proportion of sodium atoms in the vicinity of aluminum groups is lower in the as-received fibers. Since the coordination of aluminum does not change, part of aluminum groups must be charge compensated by other cations than sodium, here calcium. As a consequence, an increase of the quadrupolar splitting and thus the linewidth of the ${ }^{27} \mathrm{Al}$ MAS spectra is expected, ${ }^{47,48}$ as actually observed here. Therefore, rather than compensate the charges of $\mathrm{BO}_{4}$ and $\mathrm{AlO}_{4}$ groups, part of the sodium ions in the as-received fibers acts as additional network modifiers, probably forming non-bridging oxygen bonds with silicon groups and adopting a less homogeneous distribution. Some of $\mathrm{AlO}_{4}$ groups are Ca-compensated, while a part of $\mathrm{BO}_{4}$ is transformed into $\mathrm{BO}_{3}$ units. 

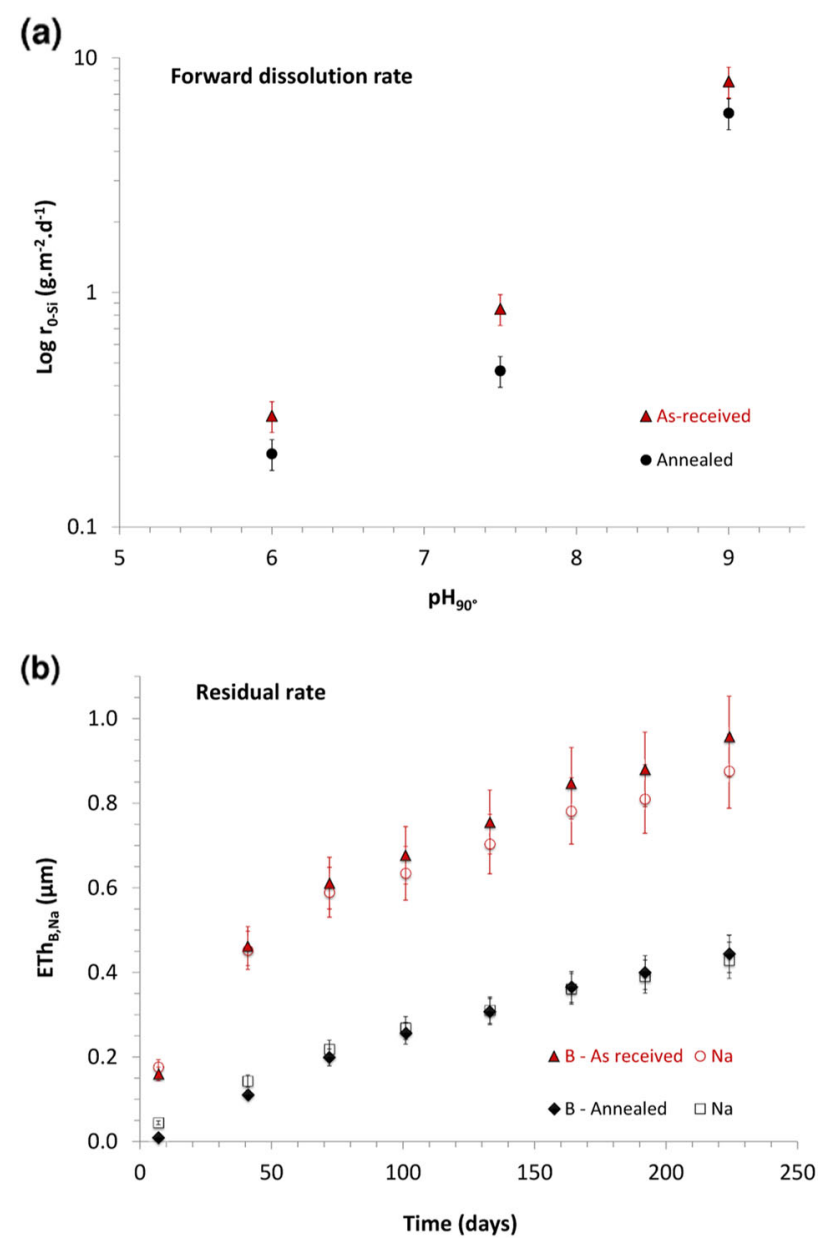

Fig. 9 a Forward dissolution rates as a function of $\mathrm{pH}$ (mean of measurements from triplicated experiments) and b equivalent thickness of the altered layer (measured from the normalized $B$ and $\mathrm{Na}$ mass losses) as a function of leaching time at $90^{\circ} \mathrm{C}$ for asreceived and annealed ISG fibers. The uncertainty in the dissolution rates and equivalent thicknesses is $10 \%$

Table 3. Chemical composition of altered layer deduced from solution analyses for ISG fibers altered for 224 days at $90^{\circ} \mathrm{C}$ and $\mathrm{pH} 9$

\begin{tabular}{lllll}
\hline Altered layer (at\%) & $\mathrm{Si}$ & $\mathrm{Al}$ & $\mathrm{Ca}$ & $\mathrm{Zr}$ \\
\hline As-received & 80.1 & 10.3 & 7.2 & 2.4 \\
Annealed & 80.3 & 10.4 & 6.9 & 2.4 \\
\hline
\end{tabular}

The non-negligible difference in thermodynamic properties also reveals the effect of structural disorder. The variation of Gibbs energy of formation between as-received and annealed fibers $\left(1.23 \mathrm{~kJ} \mathrm{~mol}^{-1}\right)$ is similar to the one between cristobalite and quartz $\left(1.7 \mathrm{~kJ} \mathrm{~mol}^{-1}\right) .^{49}$ This difference, which is substantial with respect to the intrinsic stability of the glasses, suggests that their properties also differ. The difference of Gibbs energy could here be related to a variation of mean bond energy and an increase of disorder. As for $\mathrm{SiO}_{2}$ polymorphs, the sample with the higher Gibbs energy will have a higher solubility. ${ }^{50}$ It could also reflect the impact on the observed dissolution rates.

Leaching experiments clearly point out correlations between the thermally induced structural disorder of ISG and its chemical durability in solution at different stages of alteration. Under forward dissolution rate conditions at various $\mathrm{pH}$ near neutrality, between 6 and 9 , the silicate network of the as-received fibers was hydrolyzed 1.4 to 1.8 times faster than that of the annealed fibers. Hydrolysis of the silicate glass network, which is the main mechanism governing the forward dissolution rate of the glass, is affected by the structural disorder. $\mathrm{A}$ higher $\mathrm{NBO}$ and $\mathrm{BO}_{3}$ content and possibly a lower proportion of Si second-neighbors such as $\mathrm{Zr}$ or $\mathrm{Al}$ in the as-received fibers may also facilitate the hydrolysis reactions. ${ }^{39,51,52}$ Same trends were noticed in a ternary sodium borosilicate glass with similar $\mathrm{B}_{2} \mathrm{O}_{3}$ content of about $18 \mathrm{~mol} \%$; a variation of $T_{f}$ of $46^{\circ} \mathrm{C}$ increased the $\mathrm{BO}_{3}$ of $7.9 \%$, resulting in a dissolution increase of about $1.5 .{ }^{17}$ Glass compositions with higher boron concentration were subjected to lower boron coordinence variations between quenched and annealed samples. The difference was then also less pronounced concerning the dissolution behavior. ${ }^{17}$

The experiments performed under silicon saturation conditions show that the annealed glass dissolves faster than the quenched one. The difference between the two rates is maximal at the beginning of the experiment, which corresponds to the case of a more direct glass contact with the fluid since no passivating layer has yet formed. Because the composition of the onset solutions is the same, the difference of reactivity noticed at the beginning origins from structural differences between the two pristine glasses. Next, during alteration under silica saturated conditions, structural changes occurred within alteration layer. The $\mathrm{AlO}_{4}$ et $\mathrm{ZrO}_{6}$ groups mostly charge-balanced by sodium in the pristine glass become compensated by calcium in the altered layer, as has been reported previously for other silicate glasses ${ }^{47}$ and more recently for ISG. ${ }^{53}$ While as has been shown elsewhere, ${ }^{19,43}$ boron is mostly absent from the altered layer, but trigonal boron groups are dissolved preferentially over tetrahedral units in the asreceived fiber. Possible higher $\mathrm{BO}_{3}$ grouping in the rapid quenched glass may enhance the release of mobile species in the residual rate regime. The faster residual alteration rate of the as-received fibers can also be explained by their more disordered structure (higher bond angle distribution, less-distributed alkalis and network formers around $\mathrm{Si}$ ).

During aging of the alteration layer at higher reaction progress in the residual rate regime, the rate drops quickly because of the passivation layer growth. ${ }^{19,43,54}$ Recent studies have shown that the alteration layer undergoes major reorganization owing to the high reactivity of the silicate network. ${ }^{53-55}$ It results in the formation of a microporous, hydrated, amorphous material with a large majority of non-connected pores, strongly reducing water diffusion. Moreover, as the alteration layer is an evolving material undergoing pore ripening, due to incessant hydrolysis and condensation of siloxane bonds, ${ }^{54}$ transport of aqueous species through the growing layer becomes rate-limiting. The present study points out that the residual rate of the two glasses becomes closer at longer duration. It can then be suggested that the passivating properties of the alteration layer, which are strongly linked to its reorganization, ${ }^{39,56}$ will eventually dominate glass alteration after a first step of a control by the pristine glass structure. To confirm this interpretation, more research is needed to determine water dynamics in the alteration layers formed on the two glasses.

The structural differences between the as-received and annealed fibers can be compared directly with those induced by irradiation. The decrease of $8.9 \%$ in the proportion of $\mathrm{BO}_{4}$ groups in the rapidly quenched glass is closer to the one observed in radioactive ISG doped with ${ }^{244} \mathrm{Cm}(7 \%),{ }^{12}$ than to the decrease induced in ISG by heavy-ions (Au) irradiation (13\%). ${ }^{13}$ Furthermore, whereas a change in aluminum coordination and depolymerization was observed for the irradiated glass, ${ }_{1}^{12}$ no such changes were observed either for ${ }^{244} \mathrm{Cm}$ doped $\mathrm{ISG}^{13}$ or for the quenched fibers in this study. These results therefore support the use of rapid quenching to mimic the effects of self-irradiation in nuclear glasses. This analogy could be used to study the 

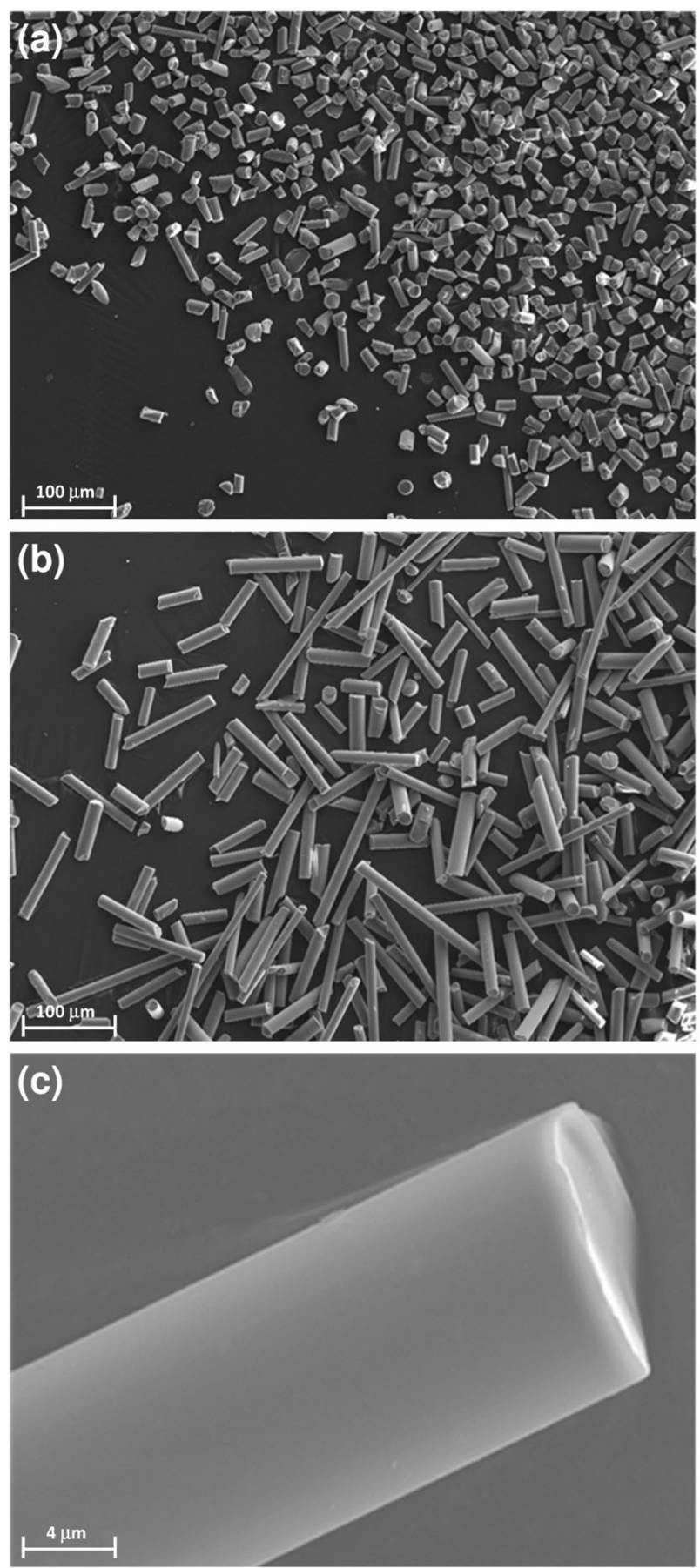

Fig. 10 Scanning electron micrographs of the chopped fibers, a $10-40 \mu \mathrm{m}$ and b $63-250 \mu \mathrm{m}$ in length. c Enlarged view of one of the fibers

mechanisms governing the chemical durability of high-activity nuclear glasses without having to handle radioactive samples.

\section{METHODS}

Sample preparation

The ISG glass $\left(60.1 \mathrm{SiO}_{2}-16.0 \mathrm{~B}_{2} \mathrm{O}_{3}-12.6 \mathrm{Na}_{2} \mathrm{O}-3.8 \mathrm{Al}_{2} \mathrm{O}_{3}-5.7 \mathrm{CaO}-1.7 \mathrm{ZrO}_{2}\right)$ used in this study was prepared by MoSci Corporation (Rolla, MO, USA) and drawn into fibers having mean diameter of $12 \mu \mathrm{m}$ by PPG industries, Inc. (Pittsburgh, PA, USA) (called "as-received fibers"). Some of the samples were annealed for $10 \mathrm{~h}$ at $575^{\circ} \mathrm{C}$ to erase their thermal history and serve as a reference (called "annealed fibers").
For the alteration rate experiments, the fibers were cut into pieces either $10-40 \mu \mathrm{m}$ or $63-250 \mu \mathrm{m}$ in length (Fig. 10). Fine particles were then removed by successive washes in acetone and absolute ethanol by sedimentation. The particles in the $10-40 \mu \mathrm{m}$ size had a geometric surface area of $1653 \mathrm{~cm}^{2} \mathrm{~g}^{-1}$ but a surface area measured using the BET method of $3475 \pm 200 \mathrm{~cm}^{2} \mathrm{~g}^{-1}$. This larger than expected surface area is due to the cutting process, which often left irregularities at the extremities of the cylinders. The geometric and BET surface areas are much closer for the larger particles, respectively $1384 \mathrm{~cm}^{2} \mathrm{~g}^{-1}$ and $1440 \pm 80 \mathrm{~cm}^{2} \mathrm{~g}^{-1}$. All the alteration rates were calculated from the BET values. Densities were measured by helium pycnometry (AccuPyc II1340, Micromeritics).

\section{NMR}

NMR data were collected on a Bruker Avance II 500WB spectrometer operating at a magnetic field of $11.72 \mathrm{~T}$, using a Bruker $4 \mathrm{~mm}$ (outer diameter of the rotor) cross-polarization MAS XH probe at a spinning rate of $12.5 \mathrm{kHz} .{ }^{11} \mathrm{~B},{ }^{23} \mathrm{Na}$, and ${ }^{27} \mathrm{Al}$ MAS NMR spectra were acquired using short $1 \mu$ s pulses (corresponding to a tip angle of about $\pi / 12$ ) to ensure a homogeneous excitation of all sites regardless of their quadrupolar coupling constant and thus obtain quantitative spectra. The recycle delays used were $1 \mathrm{~s}$ for the ${ }^{23} \mathrm{Na}$ and ${ }^{27} \mathrm{Al}$ and $2 \mathrm{~s}$ for the ${ }^{11} \mathrm{~B}$ measurements. Typically, 1024 scans were accumulated. Two types of ${ }^{11} \mathrm{~B}$ multiplequantum MAS experiments were carried out in order to optimize the signal obtained from $\mathrm{BO}_{3}$ and $\mathrm{BO}_{4}$ units, as described previously. ${ }^{26}{ }^{29} \mathrm{Si}$ MAS NMR spectra were acquired using a saturation-recovery pulse sequence with a recovery delay of $20 \mathrm{~s}$ (increasing the recycling delay did not alter the lineshape). For spin-echo and REDOR experiments, ${ }^{57,58}$ selective $90^{\circ}$ and $180^{\circ}$ pulses (frequency, $10-20 \mathrm{kHz} ; 180^{\circ}$ pulse duration of $8-10 \mu \mathrm{s}$ ) were applied on the central transition $(1 / 2 \leftrightarrow 1 / 2)$. The ${ }^{23} \mathrm{Na}-{ }^{27} \mathrm{Al}$ REDOR experiments were performed using a REDOR Box purchased from NMR Service $\mathrm{GmbH}$, which splits the X-channel of the probe into a doubleresonance circuit for close resonance frequencies (here $\nu_{0}^{\mathrm{Na}}-\nu_{0}^{\mathrm{Al}} \approx 2 \mathrm{MHz}$ ).

The ${ }^{11} \mathrm{~B},{ }^{23} \mathrm{Na},{ }^{27} \mathrm{Al}$, and ${ }^{29} \mathrm{Si} \mathrm{NMR}$ spectra were referenced externally respectively to $1 \mathrm{M}$ aqueous boric acid $(19.6 \mathrm{ppm}$ relative to boron trifluoride etherate), $1 \mathrm{M}$ aqueous $\mathrm{NaCl}(0 \mathrm{ppm}), 1.0 \mathrm{M}$ aqueous $\mathrm{Al}\left(\mathrm{NO}_{3}\right)_{3}$ $(0 \mathrm{ppm})$, and tetrakis(trimethylsilyl)silane powder (two lines at $-9.9 \mathrm{ppm}$ and $-35.3 \mathrm{ppm}$ with respect to tetramethylsilane). A correction was applied for the ${ }^{11} B$ MAS NMR spectra to account for the contribution of spinning sidebands to the $\mathrm{BO}_{4}$ centerband, as described by Hopf et al. ${ }^{51}$ The ${ }^{11} \mathrm{~B},{ }^{23} \mathrm{Na}$, and ${ }^{27} \mathrm{Al}$ MAS NMR spectra were fitted using NMR parameter distributions, as detailed elsewhere. ${ }^{26,51,59}$ A single distribution was sufficient for the ${ }^{23} \mathrm{Na}$ and ${ }^{27} \mathrm{Al}$ spectra whereas at least four lines were required for the ${ }^{11} \mathrm{~B}$ spectra, two for $\mathrm{BO}_{3}$ units and two for $\mathrm{BO}_{4}$ ones.

\section{Raman, Brillouin spectroscopies, and DSC}

Raman spectra were recorded using a Horiba iHR320 spectrometer with $1800 \mathrm{~g} \mathrm{~mm}^{-1}$ gratings, powered by a blue "Sapphire SF" $488 \mathrm{~nm}$ laser. Data were collected from 150 to $1700 \mathrm{~cm}^{-1}$. The shorter laser wavelength is favorable for recording back scattered signals because of increased Rayleigh scattering, and allows data to be recorded at high temperatures without any overlap with black body radiation. The spectra were calibrated using a calcium carbonate reference. In order to compare spectra recorded at different temperatures, they were corrected for the wavelength and temperature Raman scattering dependence, described previously. ${ }^{60}$ Brillouin spectra were recorded using a JRS TFP $2 \mathrm{HC}$ tandem multi-pass Fabry-Perot interferometer. The different heat treatments were carried out in a PerkinElmer 8500 differential scanning calorimeter that was modified to allow in situ Raman and Brillouin measurements simultaneously. The approach used, dubbed ARABICA, has been described in detail by Veber et al. ${ }^{61}$ Before each set of measurements the temperature was calibrated using $\alpha-\beta$ quartz and RbNO3 phase transitions which took place at 573 and $166^{\circ} \mathrm{C}$, respectively. All the measurements were carried out under a nitrogen gas flow of $30 \mathrm{~mL} \mathrm{~min}{ }^{-1}$

The calibration experiments were done using double side polished plane parallel plate of the ISG glass $(m=28 \mathrm{mg})$. The spectra were recorded during the heating up cycle after a period of cooling at a set rate. The cooling rates used were $300,150,75,30,15,10,5,2,1$, and $0.5 \mathrm{~K} \mathrm{~min}^{-1}$. For the in situ experiments the sample was placed in a platinum crucible covered with a pierced lid. The heating rate used was $5 \mathrm{~K} \mathrm{~min}^{-1}$ to leave enough time to properly collect Raman and Brillouin spectra. These were collected over the entire temperature range with an overall exposure time of $1.5 \mathrm{~min}$ (6 exposure cycles of $15 \mathrm{~s}$ each), such that a spectrum was recorded every $7.5^{\circ} \mathrm{C}\left(1.5 \mathrm{~min} \times 5 \mathrm{~K} \mathrm{~min}^{-1}\right)$. For the heat capacity 
measurements a completely covered crucible was used. The heat flow measured by the calorimeter was calibrated using a sapphire disk.

\section{Glass alteration experiments}

All the alteration tests were performed at $90 \pm 1{ }^{\circ} \mathrm{C}$. The forward dissolution rate $r_{0}$ was measured in highly stirred static mode using perfluoroalkoxy reactors at a low surface area to volume (SA/V) ratio of about $5 \mathrm{~m}^{-1}$. About $30 \mathrm{mg}$ of glass fiber particles $(63-250 \mu \mathrm{m}$ in size) was placed in about $500 \mathrm{~mL}$ of solution. The forward dissolution rate $\left(r_{0}\right)$ rate was measured in triplicate at $\mathrm{pH}_{90^{\circ}} 6$ (adjusted with nitric acid), $\mathrm{pH}_{90^{\circ}} 7.5$ (initially deionized water with a resistivity of $18.2 \mathrm{M} \Omega \mathrm{cm}$ ) and $\mathrm{pH}_{90^{\circ}} 9$ (adjusted with lithium hydroxide). The solution was regularly sampled and the Si concentration was determined by colorimetry with a Merck Spectroquant kit and a Cary Varian UV-visible spectrophotometer. ICP-OES analyses were performed to check the release of other elements. The $r_{0}$ values were calculated from the normalized silicon mass loss, $\mathrm{NL}(\mathrm{Si})$, and correspond to the slope of $\mathrm{NL}(\mathrm{Si})$ as a function of time. The uncertainty in $r_{0}$ was estimated to be about $10 \%$, taking into account errors in the measured surface area of the glass, in the silicon concentration, and the repeatability of the measurements. ${ }^{20}$ The residual rates $\left(r_{r}\right)$ were calculated from the normalized boron and sodium mass losses between 72 and 224 days. The associated uncertainty was also $10 \%$. Variations in the surface area of the fibers were taken into account using a shrinking core model for cylinders. ${ }^{62}$ The normalized mass losses, $\mathrm{NL}(i),\left(\mathrm{g} \mathrm{m}^{-2}\right)$ were calculated allowing for variations in the volume of the leaching solution (when samples were extracted) using the following equations:

$\mathrm{NL}(i)_{n=1}=\frac{1}{x_{i} \cdot \mathrm{SA}} \cdot V_{0} \cdot C_{j=1}$

$\mathrm{NL}(i)_{n>1}=\frac{1}{x_{i} \cdot \mathrm{SA}} \cdot\left[\left(V_{0}-\sum_{j=1}^{j=n-1} V_{j}\right) \cdot C_{j=n}+\sum_{j=1}^{j=n-1} V_{j} \cdot C_{j}\right]$

where $C_{j}$ is the concentration of element $i$ in the $j$ th sample of the solution $\left(\mathrm{g} \mathrm{m}^{-3}\right), x_{i}$ is the mass fraction of element $i$ in the glass fiber, SA is the surface area $\left(\mathrm{m}^{2}\right)$ of the glass fibers in contact with the solution, $V_{0}$ is the initial volume $\left(\mathrm{m}^{3}\right)$ of the solution in the reactor, and $V_{j}$ is the volume $\left(\mathrm{m}^{3}\right)$ of the $j$ th sample.

Residual rate $\left(r_{r}\right)$ measurements and the alteration experiments for NMR studies were carried out in non-stirred static mode using perfluoroalkoxy reactors. The altered glass studied by NMR was prepared by placing $300 \mathrm{mg}$ of glass fiber particles $(10-40 \mu \mathrm{m}$ in size) in a silicon saturated solution ([Si] $=160 \mathrm{mg} \mathrm{L}^{-1}$ ) at $\mathrm{pH}_{90^{\circ}} 7 \pm 0.2$. The SA/V ratio was $120 \mathrm{~m}^{-1}$ and the $\mathrm{pH}$ was kept constant throughout the experiment using nitric acid. For the residual rate measurements, $350 \mathrm{mg}$ of glass fiber particles $\left(10-40 \mu \mathrm{m}\right.$ in size) was altered at a SA $/ \mathrm{V}$ ratio of $150 \mathrm{~m}^{-1}$ in a silicon saturated solution ([Si] $=260 \mathrm{mg} \mathrm{L}^{-1}$ ) at $\mathrm{pH}_{90^{\circ}} 9 \pm 0.1$ (adjusted using lithium hydroxide). The $\mathrm{pH}$ of the solution remained constant throughout the experiment without any additional $\mathrm{LiOH}$ being required.

\section{DATA AVAILABILITY}

The data that support the findings of this study are available from the corresponding author upon reasonable request.

\section{ACKNOWLEDGEMENTS}

This work was supported by the French Alternative Energies and Atomic Energy Commission (CEA), ORANO and EDF.

\section{AUTHOR CONTRIBUTIONS}

F.A. and T.C. initiated the project. F.A. supervised the study and wrote the paper. T.C. performed the solid-state NMR study. P.J. performed the alteration experiments. D.d. L., M.B., and A.V. performed the Raman, Brillouin spectroscopies and DSC measurements. S.G. was involved in data interpretation. H.L. provided fibers from ISG glass. All the authors helped on paper writing and editing.

\section{ADDITIONAL INFORMATION}

Competing interests: The authors declare no competing interests.

Publisher's note: Springer Nature remains neutral with regard to jurisdictional claims in published maps and institutional affiliations.

\section{REFERENCES}

1. Devreux, F., Cailleteau, C. \& Barboux, P. Evidence for a threshold in the biosolubility of aluminosilicate vitreous fibers. J. Mater. Sci. 45, 1154-1159 (2010).

2. Kump, L. R., Brantley, S. L. \& Arthur, M. A. Chemical, weathering, atmospheric CO2, and climate. Annu. Rev. Earth Planet. Sci. 28, 611-667 (2000).

3. Angeli, F., Jollivet, P., Charpentier, T., Fournier, M. \& Gin, S. Structure and chemical durability of lead crystal glass. Environ. Sci. Technol. 50, 11549-11558 (2016).

4. Werme, L. et al. Chemical corrosion of highly radioactive borosilicate nuclear waste glass under simulated repository conditions. J. Mater. Res. 5, 1130-1146 (1990).

5. Poinssot, C. \& Gin, S. Long-term behavior science: the cornerstone approach for reliably assessing the long-term performance of nuclear waste. J. Nucl. Mater. 420, 182-192 (2012).

6. Gin, S., Beaudoux, X., Angéli, F., Jégou, C. \& Godon, N. Effect of composition on the short-term and long-term dissolution rates of ten borosilicate glasses of increasing complexity from 3 to 30 oxides. J. Non-Cryst. Solids 358, 2559-2570 (2012).

7. Angeli, F. et al. Effect of temperature and thermal history on borosilicate glass structure. Phys. Rev. B 85, 054110 (1-14) (2012).

8. Peuget, $S$. et al. Comparison of radiation and quenching rate effects on the structure of a sodium borosilicate glass. J. Non-Cryst. Solids 378, 201-212 (2013).

9. Delaye, J. M., Peuget, S., Bureau, G. \& Calas, G. Molecular dynamics simulation of radiation damage in glasses. J. Non-Cryst. Solids 357, 2763-2768 (2011).

10. Maugeri, E. A. et al. Calorimetric study of glass structure modification induced by a decay. J. Am. Ceram. Soc. 95, 2869-2875 (2012).

11. Peuget, S., Delaye, J. M. \& Jegou, C. Specific outcomes of the research on the radiation stability of the French nuclear glass towards alpha decay accumulation. J. Nucl. Mater. 444, 76-91 (2014).

12. Charpentier, T. et al. Self-healing capacity of nuclear glass observed by NMR spectroscopy. Sci. Rep. 6, 6 (2016).

13. Mendoza, C. et al. Oxide glass structure evolution under swift heavy ion irradiation. Nucl. Instrum. Methods Phys. Res. Sect. B-Beam Interact. Mater. At. 325, 54-65 (2014).

14. Mir, A. H. et al. Mono and sequential ion irradiation induced damage formation and damage recovery in oxide glasses: stopping power dependence of the mechanical properties. J. Nucl. Mater. 469, 244-250 (2016).

15. Ya, M., Deubener, J. \& Yue, Y. Z. Enthalpy and anisotropy relaxation of glass fibers. J. Am. Ceram. Soc. 91, 745-752 (2008).

16. Amma, S., Luo, J. W., Kim, S. H. \& Pantano, C. G. Effects of fictive temperature on the leaching of soda lime silica glass surfaces. J. Am. Ceram. Soc. 100, 1424-1431 (2017).

17. Stone-Weiss, N. et al. Understanding the structural drivers governing glass-water interactions in borosilicate based model bioactive glasses. Acta Biomater. 65, 436-449 (2018).

18. Gin, S. et al. An international initiative on long-term behavior of high-level nuclear waste glass. Mater. Today 16, 243-248 (2013).

19. Gin, S. et al. Origin and consequences of silicate glass passivation by surface layers. Nat. Commun. 6, 8 (2015).

20. Fournier, M. et al. Glass dissolution rate measurement and calculation revisited. J. Nucl. Mater. 476, 140-154 (2016).

21. Levelut, C., Le Parc, R., Faivre, A. \& Champagnon, B. Influence of thermal history on the structure and properties of silicate glasses. J. Non-Cryst. Solids 352, 4495-4499 (2006).

22. Guerette, M. \& Huang, L. P. In-situ Raman and Brillouin light scattering study of the international simple glass in response to temperature and pressure. J. NonCryst. Solids 411, 101-105 (2015).

23. Deng, L. \& Du, J. C. Effects of system size and cooling rate on the structure and properties of sodium borosilicate glasses from molecular dynamics simulations. J. Chem. Phys. 148, 14 (2018).

24. Konijnendijk, W. L. \& Stevels, J. M. Structure of borosilicate glasses studied by Raman-scattering. J. Non-Cryst. Solids 20, 193-224 (1976).

25. Shibata, N., Horigudhi, M. \& Edahiro, T. Raman-spectra of binary high-silica glasses and fibers containing GeO2 P2O5 and B2O3. J. Non-Cryst. Solids 45, 115-126 (1981).

26. Angeli, F., Charpentier, T., de Ligny, D. \& Cailleteauz, C. Boron speciation in sodalime borosilicate glasses containing zirconium. J. Am. Ceram. Soc. 93, 2693-2704 (2010).

27. Bunker, B. C., Tallant, D. R., Kirkpatrick, R. J. \& Turner, G. L. Multinuclear nuclearmagnetic-resonance and Raman investigation of sodium borosilicate glass structures. Phys. Chem. Glass. 31, 30-41 (1990).

28. Mysen, B. O., Finger, L. W., Virgo, D. \& Seifert, F. A. Curve-fitting of Raman-spectra of silicate-glasses. Am. Miner. 67, 686-695 (1982).

29. McMillan, P. Structuralstudies of silicate-glasses and melts - applications and limitations of raman-spectroscopy. Am. Miner. 69, 622-644 (1984). 
30. Yue, Y. Z. Characteristic temperatures of enthalpy relaxation in glass. J. Non-Cryst. Solids 354, 1112-1118 (2008).

31. Linard, Y., Yamashita, I., Atake, T., Rogez, J. \& Richet, P. Thermochemistry of nuclear waste glasses: an experimental determination. J. Non-Cryst. Solids 286, 200-209 (2001).

32. Angeli, F. et al. Influence of lanthanum on borosilicate glass structure: a multinuclear MAS and MQMAS NMR investigation. J. Non-Cryst. Solids 376, 189-198 (2013).

33. Soleilhavoup, A., Delaye, J. M., Angeli, F., Caurant, D. \& Charpentier, T. Contribution of first-principles calculations to multinuclear NMR analysis of borosilicate glasses. Magn. Reson. Chem. 48, S159-S170 (2010).

34. Florian, P., Veron, E., Green, T. F. G., Yates, J. R. \& Massiot, D. Elucidation of the Al/ $\mathrm{Si}$ ordering in gehlenite $\mathrm{Ca} 2 \mathrm{Al} 2 \mathrm{SiO} 7$ by combined $\mathrm{Si}-29$ and Al-27 NMR spectroscopy/quantum chemical calculations. Chem. Mater. 24, 4068-4079 (2012).

35. Nanba, T., Asano, Y., Benino, Y., Sakida, S. \& Miura, Y. Molecular orbital calculation of the Si-29 NMR chemical shift in borosilicates: the effect of boron coordination to SiO4 units. Phys. Chem. Glass.-Eur. J. Glass Sci. Technol. Part B 50, 301-304 (2009).

36. Nanba, T., Nishimura, M. \& Miura, Y. A theoretical interpretation of the chemical shift of Si-29 NMR peaks in alkali borosilicate glasses. Geochim. Cosmochim. Acta 68, 5103-5111 (2004).

37. Ratai, E., Janssen, M. \& Eckert, H. Spatial distributions and chemical environments of cations in single- and mixed alkali borate glasses: evidence from solid state NMR. Solid State lon. 105, 25-37 (1998).

38. Gullion, T. \& Schaefer, J. Rotational-echo double-resonance NMR. J. Magn. Reson. 81, 196-200 (1989)

39. Cailleteau, C. et al. Insight into silicate-glass corrosion mechanisms. Nat. Mater. 7, 978-983 (2008)

40. Vienna, J. D., Ryan, J. V., Gin, S. \& Inagaki, Y. Current understanding and remaining challenges in modeling long-term degradation of borosilicate nuclear waste glasses. Int. J. Appl. Glass Sci. 4, 283-294 (2013).

41. Frugier, P. et al. SON68 nuclear glass dissolution kinetics: current state of knowledge and basis of the new GRAAL model. J. Nucl. Mater. 380, 8-21 (2008).

42. Advocat, T., Crovisier, J. L., Vernaz, E., Ehret, G. \& Charpentier, H. Hydrolysis of R7t7 Nuclear Waste Glass In Dilute Media - Mechanisms and Rate as a Function of $\mathrm{pH}$. Vol. 212 (Materials Research Soc., Boston, 1991).

43. Gin, S. et al. Atom-probe tomography, TEM and ToF-SIMS study of borosilicate glass alteration rim: a multiscale approach to investigating rate-limiting mechanisms. Geochim. Cosmochim. Acta 202, 57-76 (2017).

44. Neuville, D. R., de Ligny, D. \& Henderson, G. S. in Spectroscopic Methods in Mineralology and Materials Sciences, Vol. 78 (eds G. S. Henderson, D. R. Neuville \& R. T. Downs) 509-541 (Mineralogical Society of America, Chantilly, 2014).

45. Matson, D. W., Sharma, S. K. \& Philpotts, J. A. The structure of high-silica alkalisilicate glasses. A Raman spectroscopic investigation. J. Non-Cryst. Solids $\mathbf{5 8}$ 323-352 (1983)

46. Angeli, F., Villain, O., Schuller, S., Ispas, S. \& Charpentier, T. Insight into sodium silicate glass structural organization by multinuclear NMR combined with firstprinciples calculations. Geochim. Cosmochim. Acta 75, 2453-2469 (2011).

47. Angeli, F., Gaillard, M., Jollivet, P. \& Charpentier, T. Influence of glass composition and alteration solution on leached silicate glass structure: a solid-state NMR investigation. Geochim. Cosmochim. Acta 70, 2577-2590 (2006).

48. Angeli, F., Gaillard, M., Jollivet, P. \& Charpentier, T. Contribution of Ca-43 MAS NMR for probing the structural configuration of calcium in glass. Chem. Phys. Lett. 440, 324-328 (2007).
49. Robie, R. A. \& Hemingway, B. S. Thermodynamic Properties of Minerals and Related Substances at $298.15 \mathrm{~K}$ and $1 \mathrm{Bar}(105 \mathrm{~Pa})$ Pressures and at Higher Temperatures. Vol. 2131 (US Geological Survey Bulletin, Washington, 1995).

50. Fournier, R. O. \& Rowe, J. J. Solubility of cristobalite along 3-phase curve, gas plus liquid plus cristobalite. Am. Miner. 47, 897-89 (1962).

51. Hopf, J. et al. Glass-water interaction: effect of high-valence cations on glass structure and chemical durability. Geochim. Cosmochim. Acta 181, 54-71 (2016).

52. Bergeron, B. et al. First investigations of the influence of IVB elements ( $\mathrm{Ti}$, $\mathrm{Zr}$, and $\mathrm{Hf}$ ) on the chemical durability of soda-lime borosilicate glasses. J. Non-Cryst. Solids 356, 2315-2322 (2010).

53. Collin, M. et al. Structure of international simple glass and properties of passivating layer formed in circumneutral pH conditions. npj Mater. Degrad. 2, 4 (2018).

54. Gin, S. et al. Dynamics of self-reorganization explains passivation of silicate glasses. Nat. Commun. 9, 2169 (2018)

55. Collin, M., Fournier, M., Charpentier, T., Moskura, M. \& Gin, S. Impact of alkali on the passivation of silicate glass. npj Mater. Degrad. 2, 16 (2018)

56. Cailleteau, C., Devreux, F., Spalla, O., Angeli, F. \& Gin, S. Why do certain glasses with a high dissolution rate undergo a low degree of corrosion? J. Phys. Chem. $C$ 115, 5846-5855 (2011).

57. Bertmer, M., Zuchner, L., Chan, J. C. C. \& Eckert, H. Short and medium range order in sodium aluminoborate glasses. 2. Site connectivities and cation distributions studied by rotational echo double resonance NMR spectroscopy. J. Phys. Chem. B 104, 6541-6553 (2000)

58. Janssen, M. \& Eckert, H. B-11\{Na-23\} rotational echo double resonance NMR: a new approach for studying the spatial cation distribution in sodium borate glasses. Solid State Ion. 136, 1007-1014 (2000).

59. Quintas, A. et al. NMR study of a rare-earth aluminoborosilicate glass with varying CaO-to-Na2O ratio. Appl. Magn. Reson. 32, 613-634 (2007).

60. McMillan, P. F., Poe, B. T., Gillet, P. \& Reynard, B. A study of $\mathrm{SiO} 2$ glass and supercooled liquid to $1950 \mathrm{~K}$ via high-temperature raman-spectroscopy. Geochim. Cosmochim. Acta 58, 3653-3664 (1994).

61. Veber, A., Cicconi, M. R., Reinfelder, H. \& de Ligny, D. Combined differential scanning calorimetry, Raman and Brillouin spectroscopies: a multiscale approach for materials investigation. Anal. Chim. Acta 998, 37-44 (2018).

62. Gin, S., Frugier, P., Jollivet, P., Bruguier, F. \& Curti, E. New insight into the residual rate of borosilicate glasses: effect of $\mathrm{S} / \mathrm{V}$ and glass composition. Int. J. Appl. Glass Sci. 4, 371-382 (2013).

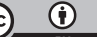

Open Access This article is licensed under a Creative Commons Attribution 4.0 International License, which permits use, sharing, adaptation, distribution and reproduction in any medium or format, as long as you give appropriate credit to the original author(s) and the source, provide a link to the Creative Commons license, and indicate if changes were made. The images or other third party material in this article are included in the article's Creative Commons license, unless indicated otherwise in a credit line to the material. If material is not included in the article's Creative Commons license and your intended use is not permitted by statutory regulation or exceeds the permitted use, you will need to obtain permission directly from the copyright holder. To view a copy of this license, visit http://creativecommons. org/licenses/by/4.0/.

(c) The Author(s) 2018 